\title{
Bebida e Sobremesas Lácteas Probióticas: Viabilidade de Lactobacillus casei nos Produtos e Sua Resistência em Condições Simuladas do Trato Gastrointestinal Humano
}

Fernanda Diekmann Mantovani (I), Angélica Basso Kimura (I), Kawanna Cristina de Lima (I), Cínthia Hoch Batista de Souza (I), Elsa Helena Walter de Santana (I), Lina Casale Aragon-Alegro (I)

(I) UNOPAR - Universidade Norte do Paraná (Av. Paris, 675, Jd Piza)

\section{Resumo}

Probióticos são micro-organismos vivos, que quando consumidos em quantidades adequadas são capazes de conferir efeitos benéficos à saúde do hospedeiro. A administração correta e regular pode assegurar a prevenção de patologias, regulação da microbiota intestinal, distúrbios do metabolismo gastrointestinal, imunomoduladores e na inibição da carcinogênese. Porém, para que exerçam esses efeitos benéficos, os alimentos devem conter culturas probióticas viáveis, com populações acima de 106 Unidades Formadoras de Colônias (UFC)/g ou mL, durante todo período de validade do produto, além de sobreviverem à passagem pelo trato gastrointestinal. Esta pesquisa propôs a elaboração de um flan de chocolate, um flan de maracujá e uma bebida láctea sabor chocolate, todos probióticos. Para isso, no dia seguinte da fabricação dos produtos lácteos e após 7, 14 e 21 dias, foram determinados o pH, a acidez e a viabilidade do micro-organismo probiótico Lactobacillus casei nos três produtos supracitados. Nos mesmos períodos, a viabilidade desse micro-organismo foi avaliada após passagem em caldos que simularam as condições do trato gastrointestinal (fase gástrica, primeira fase entérica e segunda fase entérica). A fim de caracterizar os produtos elaborados, análises de composição centesimal foram realizadas após um dia da data de fabricação.

\footnotetext{
Referência:

Fernanda Diekmann Mantovani, Angélica Basso Kimura, Kawanna Cristina de Lima, Cínthia Hoch Batista de Souza, Elsa Helena Walter de Santana, Lina Casale Aragon-Alegro. Bebida e Sobremesas Lácteas Probióticas: Viabilidade de Lactobacillus casei nos Produtos e Sua Resistência em Condições Simuladas do Trato Gastrointestinal Humano. In: Anais do $12^{\circ}$ Congresso Latinoamericano de Microbiologia e Higiene de Alimentos - MICROAL 2014 [= Blucher Food Science Proceedings, num.1, vol.1]. São Paulo: Editora Blucher, 2014. DOI $10.5151 /$ foodsci-microal-228
} 
Todo o experimento foi realizado em triplicata, e os dados avaliados através de análise de variância (ANOVA) e teste de Tukey, utilizando o programa Statistica. O Lactobacillus casei manteve-se viável e em populações acima de $6 \log$ UFC g ou mL nos três produtos avaliados, apresentando maiores populações na bebida láctea. Quando submetido à simulação das condições gástricas, a população de Lactobacillus casei nos diferentes produtos apresentou redução entre 4 e 5 ciclos logarítmicos. A bebida láctea e o flan de maracujá apresentaram populações maiores de Lactobacillus casei quando comparadas com o flan de chocolate. Apesar disso, o micro-organismo probiótico proveniente deste último, quando submetido às condições entéricas, recuperou-se mais rapidamente que os presentes nos outros produtos.

Palavras-Chave: flan, probiótico, intestino delgado, intestino grosso, estômago

Agência de Fomento: Capes 